\title{
Strategies for genetic inactivation of long noncoding RNAs in zebrafish
}

\author{
PERRINE LAVALOU, HELENE ECKERT, LOUISE DAMY, FLORIAN CONSTANTY, SARA MAJELLO, \\ ANGELO BITETTI, ANTOINE GRAINDORGE, and ALENA SHKUMATAVA
}

Institut Curie, PSL Research University, CNRS UMR3215, INSERM U934, 75005 Paris, France

\begin{abstract}
The number of annotated long noncoding RNAs (IncRNAs) continues to grow; however, their functional characterization in model organisms has been hampered by the lack of reliable genetic inactivation strategies. While partial or full deletions of IncRNA loci disrupt IncRNA expression, they do not permit the formal association of a phenotype with the encoded transcript. Here, we examined several alternative strategies for generating IncRNA null alleles in zebrafish and found that they often resulted in unpredicted changes to IncRNA expression. Removal of the transcription start sites (TSSs) of IncRNA genes resulted in hypomorphic mutants, due to the usage of either constitutive or tissue-specific alternative TSSs. Deletions of short, highly conserved IncRNA regions can also lead to overexpression of truncated transcripts. In contrast, knock-in of a polyadenylation signal enabled complete inactivation of malat1, the most abundant vertebrate IncRNA. In summary, IncRNA null alleles require extensive in vivo validation, and we propose insertion of transcription termination sequences as the most reliable approach to generate IncRNA-deficient zebrafish.
\end{abstract}

Keywords: CRISPR-Cas9; hypomorph; long noncoding RNAs; poly(A) signal; zebrafish

\section{INTRODUCTION}

Thousands of IncRNAs have been identified in multiple vertebrate species (Necsulea et al. 2014; Hezroni et al. 2015), but their biological functions remain mostly unknown. To study IncRNAs in vivo, genetic mutants have been generated in model animals, primarily using a mouse model (Leighton et al. 1995; Marahrens et al. 1997; Ripoche et al. 1997; Sado et al. 2001; Sleutels et al. 2002; Bond et al. 2009; Eissmann et al. 2012; Nakagawa et al. 2012, 2014; Zhang et al. 2012; Grote et al. 2013; Li et al. 2013; Sauvageau et al. 2013; Han et al. 2014, 2018; Goff and Rinn 2015; Lai et al. 2015; Amândio et al. 2016; Anderson et al. 2016; Ip et al. 2016; Kotzin et al. 2016; Isoda et al. 2017; Kleaveland et al. 2018), but have also more recently been reported in zebrafish (Kok et al. 2015; Hosono et al. 2017; Bitetti et al. 2018; Goudarzi et al. 2019).

Genetic inactivation of IncRNAs is less straightforward than for coding genes, where deletion of an exon or a point mutation in the open reading frame (ORF) often leads to stop codons or frame-shift mutations and subsequent loss of function. Several complementary strategies have been implemented to achieve genetic loss of IncRNA func-

Corresponding author: alena.shkumatava@curie.fr

Article is online at http://www.rnajournal.org/cgi/doi/10.1261/rna. 069484.118. Freely available online through the RNA Open Access option. tion, including full or partial deletion of the IncRNA locus, deletion and subsequent replacement of the IncRNA locus by a reporter gene (Nakagawa et al. 2012; Sauvageau et al. 2013), deletion of the IncRNA transcription start site (TSS) and upstream regulatory regions (Fitzpatrick et al. 2002; Zhang et al. 2012) and sequence inversions (Fig.1; Bitetti et al. 2018). Although commonly used, these IncRNA inactivation strategies have several caveats and limitations. Full deletions of IncRNA loci, which often span several kilobases, or IncRNA replacement by a reporter gene are invasive and might lead to phenotypes that are caused by removal of regulatory DNA motifs. Deletions of IncRNA TSS and upstream promoter regions may result in usage of alternative TSSs or cryptic promoters and/or impact the expression of neighboring genes. A less invasive and more accurate approach is to inactivate IncRNAs by integrating a premature polyadenylation [poly(A)] cassette. This strategy has been successfully implemented in several recent mouse IncRNA studies (Fig. 1; Bond et al. 2009; Grote et al. 2013; Anderson et al. 2016; Ballarino et al. 2018). Whereas IncRNA locus deletion and partial IncRNA gene inversion strategies have been applied in zebrafish to genetically inactivate IncRNAs (Kok et al. 2015; Hosono et al. 2017; Bitetti et al. 2018; Goudarzi

(C) 2019 Lavalou et al. This article, published in RNA, is available under a Creative Commons License (Attribution 4.0 International), as described at http://creativecommons.org/licenses/by/4.0/. 


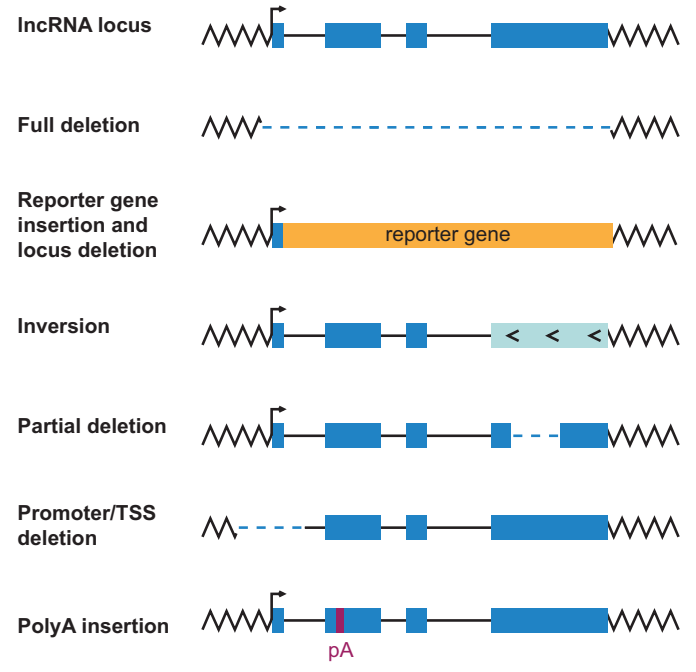

FIGURE 1. Strategies for genetic inactivation of IncRNAs in animals.

et al. 2019), analyses of complementary IncRNA silencing approaches including the minimally invasive insertion of the poly(A) sequences have not yet been carried out.

Here, we examined the efficiency of several strategies for CRISPR-Cas9-mediated inactivation of IncRNAs in zebrafish. Careful evaluation of IncRNA zebrafish mutants demonstrated that caution is required when analyzing each individual mutant allele. When genetically manipulating IncRNA loci, we found that usage of constitutive or tissue-specific alternative TSSs, overexpression or destabilization of truncated IncRNA transcripts commonly take place in vivo, minimizing or confounding the effect of the intended genetic intervention. In contrast, using our minimally invasive knock-in of a premature polyadenylation signal into the malat1 locus diminished malat1 transcripts to undetectable levels, effectively establishing a malat1 null allele in zebrafish.

\section{RESULTS}

\section{Deletion of the conserved region of the IncRNA cyrano leads to overexpression of the truncated transcript}

A small fraction of zebrafish IncRNAs are conserved in mammals, representing a promising set of candidates for functional interrogation (Ulitsky et al. 2011; Hezroni et al. 2015). The conserved regions of IncRNAs are usually relatively short, ranging between 50-300 nucleotides (nt) (Ulitsky et al. 2011; Hezroni et al. 2015) and can be efficiently targeted for CRISPR-Cas9-mediated deletions in zebrafish, offering a minimally invasive strategy for functional inactivation (Fig. 1). To examine the effect of this strategy on IncRNA expression, we chose the deeply conserved IncRNA cyrano (Ulitsky et al. 2011) for genetic inter- rogations in zebrafish. We generated a 280 base pair (bp) deletion of the most conserved region of the $5.5 \mathrm{~kb}$ sequence, hereafter referred as cyrano ${ }^{\Delta C R}$ (Fig. 2A,B; Ulitsky et al. 2011). Interestingly, we detected elevated levels of the residual truncated transcript in homozygous cyrano $^{\Delta C R}$ zebrafish embryos and across cyrano ${ }^{\Delta C R}$ adult tissues apart from the brain (Fig. 2C,D; Supplemental Fig. 1A). These results suggest that removal of a relatively small region of a IncRNA may have an unexpected effect on the transcript levels, potentially leading to its unintended overexpression.

\section{TSS deletion of the cyrano locus results in hypomorphic zebrafish mutants}

Next, we tested if deleting the sequences surrounding and containing IncRNA TSS elements is a reliable alternative strategy for zebrafish IncRNA genetic inactivation. To this end, we generated a minimally invasive cyrano ${ }^{\Delta T S S}$ mutant allele by removing sequences containing the cyrano TSS $(0$ to +84$)$ (Fig. 2E). Although cyrano transcript levels were reduced in cyrano ${ }^{\Delta T S S}$ fish, the transcript was still robustly detectable by RNA blot analysis and QRT-PCR, resulting in a hypomorphic cyrano ${ }^{\Delta T S S}$ mutant (Fig. 2F,G). The 5' RACE (rapid amplification of cDNA ends) analysis demonstrated that in the absence of the two main TSSs usually used in WT animals, an alternative upstream TSS maintains cyrano expression in cyrano ${ }^{\Delta T S S}$ mutant zebrafish (Supplemental Fig. 1B-D).

Notably, neither the cyrano ${ }^{\Delta C R}$ mutant, with removal of the highly conserved miR-7 site (Ulitsky et al. 2011), nor the cyrano ${ }^{\Delta T S S}$ mutant fish exhibited obvious morphological defects. This observation is consistent with recent zebrafish and mouse studies (Kleaveland et al. 2018; Goudarzi et al. 2019) and is in contrast to previous studies that used a morpholino-based knockdown approach to inactivate cyrano (Ulitsky et al. 2011; Sarangdhar et al. 2018).

\section{IncRNA TSS removal leads to tissue-specific alternative TSS usage, maintaining IncRNA expression}

To test if the usage of alternative TSSs is a prevalent cellular mechanism to maintain IncRNA gene expression, we examined the effect of TSS deletions on additional IncRNAs in zebrafish. We generated a Inc-sox4a ${ }^{\Delta T S S}$ mutant allele by removing $\sim 200$ bp surrounding the Inc-sox4a TSS $(-43$ to +157) (Fig. 3A,B). Inc-sox4a (chr19:29,161,67629,270,573; Zv9/danRer7) (Ulitsky et al. 2011) is highly expressed in the zebrafish ovary and was successfully abolished in Inc-sox4a ${ }^{\Delta T S S}$ embryos and across Inc-sox $4 a^{\Delta T S S}$ adult tissues (Fig. 3C,D). However, Inc-sox4a was robustly expressed in the adult Inc-sox $4 a^{4 T S S}$ brain at levels comparable to WT (Fig. 3D). The 5' RACE analysis confirmed that a tissue-specific alternative TSS, located in an intron $70 \mathrm{~kb}$ 
A

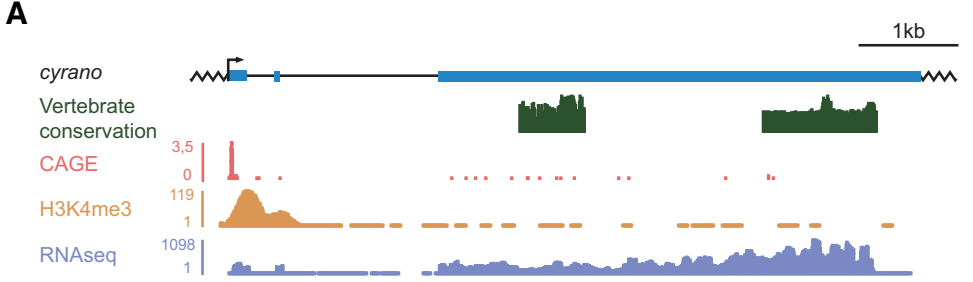

B

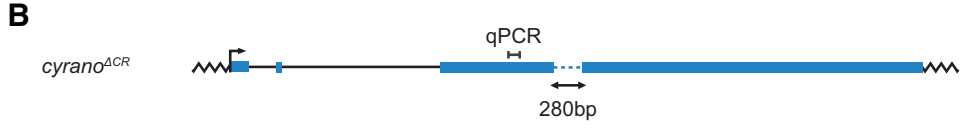

C

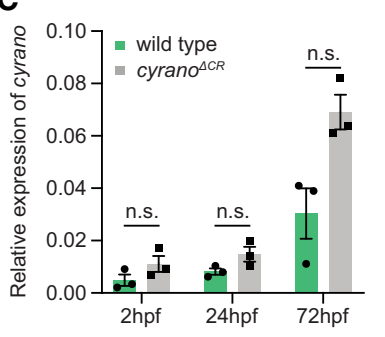

D
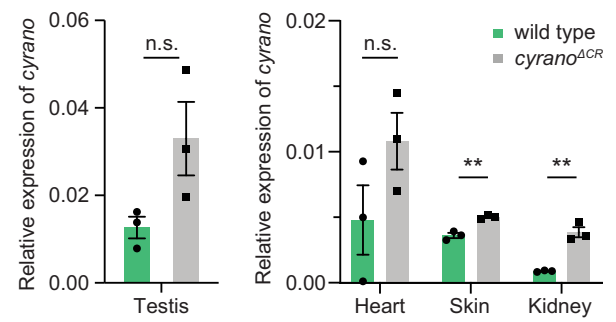

E

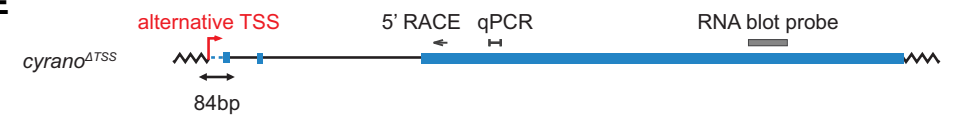

$\mathbf{F}$

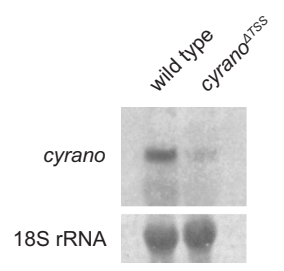

G

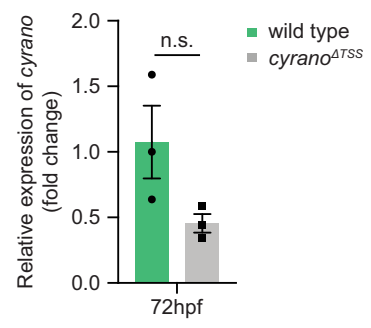

FIGURE 2. Genetic perturbations of the IncRNA cyrano in zebrafish result in overexpression and hypomorphic alleles. (A) Gene architecture of the IncRNA cyrano. Shown are the corresponding CAGE (Nepal et al. 2013; Haberle et al. 2014), H3K4me3 ChIP-Seq (Ulitsky et al. 2011), and RNA-seq tracks from wild-type (WT) zebrafish. Vertebrate conservation plots based on the eight-genome alignment indicate the location of conserved sequences. $(B)$ The cyrano $^{\Delta C R}$ mutant allele showing the deletion of the most conserved region of the transcript (dotted, blue line) in zebrafish. Position of the qRT-PCR product is indicated. (C) cyrano expression in WT and homozygous cyrano ${ }^{\Delta C R}$ embryos detected by qRT-PCR at $2 \mathrm{~h}$ postfertilization (hpf), 24 and 72 hpf. (D) cyrano expression across WT and homozygous cyrano ${ }^{\Delta C R}$ adult tissues detected by qRT-PCR. (E) The cyrano ${ }^{\Delta T S S}$ zebrafish allele showing deletion of the sequence around the TSS (dotted, blue line). Indicated are positions of the 5' RACE primer, qPCR product, RNA blot probe and alternative TSS. (F) cyrano expression in $72 \mathrm{hpfWT}$ and homozygous cyrano $^{\Delta T S S}$ embryos detected by an RNA blot. $18 \mathrm{~S}$ rRNA was used as a reference gene. (G) cyrano expression in $72 \mathrm{hpf} W T$ and homozygous cyrano ${ }^{\Delta T S S}$ embryos detected by qRT-PCR. eef1 $\alpha 1 / 1$ was used as a reference gene in all qRT-PCR experiments. Each dot represents an individual biological replicate. Data are presented as mean \pm S.E.M.; $\left.{ }^{*}\right) P<0.05$, n.s., not significant, unpaired t-tests.

downstream from the main TSS (Fig. 3B; Supplemental Fig. $2 A, B)$, was used only in the lnc-sox $4 a^{\Delta T S S}$ animals and maintained IncRNA expression specifically in the adult brain (Fig. 3D). While homozygous Inc-sox $4 a^{\Delta T S S}$ fish were viable and fertile, our alternative strategy to eliminate Inc-sox4a expression by deleting the last exon failed to generate homozygous fish (Supplemental Fig. 2C,D).

We generated an additional IncRNA mutant by removing $\sim 390$ bp surrounding the Inc-pou2af1 TSS $(-74$ to +315$)$ (Fig. 4A,B). Similar to the Inc-sox $4 a^{\Delta T S S}$ allele, the level of Inc-pou2af1 (chr15:16770170-16773 603; Zv9/danRer7) was abolished in Inc-pou $2 a f 1^{\triangle T S S}$ embryos and in a subset of tested Inc-pou2af1 ${ }^{\Delta T S S}$ adult tissues (Fig. 4C; Supplemental Fig. 3A). However, in skin, kidney, intestine and testis, expression of Inc-pou2af1 was robustly detected in Incpou2af1 ${ }^{\Delta T S S}$ fish (Fig. 4D,E). The $5^{\prime}$ RACE analysis showed that several alternative TSSs, located $\sim 1 \mathrm{~kb}$ upstream of the main TSS, were used in the Inc-pou2af1 ${ }^{4 T S S}$ animals in a tissue-specific manner (Fig. 4B; Supplemental Fig. 3B,C). Expression of Inc-pou2af1 from alternative TSSs generated new tissue-specific IncRNA exons at the $5^{\prime}$ of the transcript (Fig. 4B; Supplemental Fig. 3C,D).

Together, our data showed that in the absence of the main TSS, alternative TSSs can be used in a tissue-specific manner, generating hypomorphic mutants, and minimizing the effect of the intended gene inactivation.

\section{Insertion of a polyadenylation signal resulted in a malat1 null allele in zebrafish}

Given the evidence that usage of alternative TSSs may be a common cellular mechanism to confer IncRNA expression, we tested if knock-in of a poly(A) signal into a IncRNA locus can be applied in zebrafish as a minimally invasive alternative to generate IncRNA null alleles. This approach has been successfully used to inactivate IncRNAs in mice (Grote et al. 2013; Anderson et al. 2016; Isoda et al. 2017; Ballarino et al. 2018). The malat1 locus produces one of the most abundant IncRNAs in vertebrate genomes (Ulitsky et al. 2011; Hezroni et al. 2015). Because malat1 is a mono-exonic IncRNA of $\sim 7.5 \mathrm{~kb}$ and its locus contains multiple TSSs and clustered enhancers forming a so-called super-enhancer (Pérez-Rico et al. 2017), any deletion strategy of the locus, including TSS removal, has a strong potential 
A

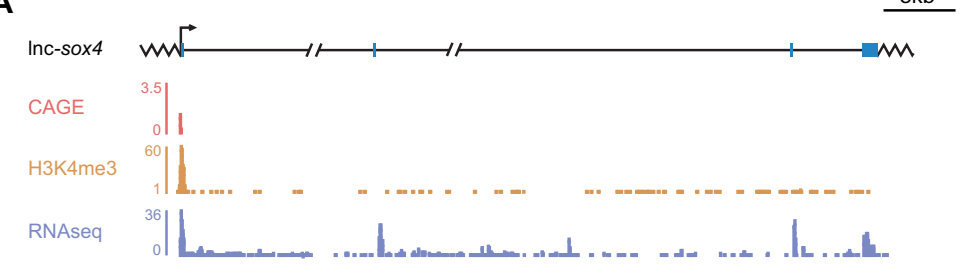

B
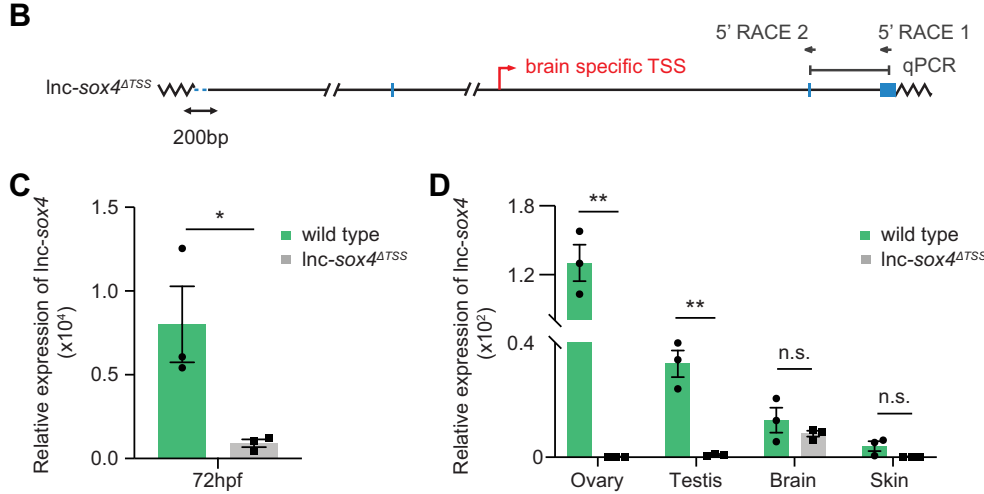

FIGURE 3. Presence of a tissue-specific alternative TSS leads to a brain-specific rescue of Incsox4a expression. (A) The Inc-sox4a locus in zebrafish (chr19:29,161,676-29,270,573). Shown are the corresponding CAGE (Nepal et al. 2013; Haberle et al. 2014), H3K4me3 ChIP-Seq (Ulitsky et al. 2011), and RNA-seq tracks from WT zebrafish. (B) The lnc-sox4a ${ }^{\Delta T S S}$ mutant allele showing deletion of the sequence around the TSS (dotted, blue line). Indicated are positions of the 5' RACE primers, qPCR primers, and alternative TSS. (C) Inc-sox4a expression in $72 \mathrm{~h}$ postfertilization (hpf) WT and homozygous Inc-sox $4 a^{\Delta T S S}$ embryos detected by qRT-PCR. (D) Incsox4a expression across adult WT and homozygous Inc-sox $4 a^{\Delta T S S}$ zebrafish tissues detected by qRT-PCR. eef1 $\alpha 111$ was used as a reference gene in all qRT-PCR experiments. Each dot represents an individual biological replicate. Data are presented as mean \pm S.E.M.; $\left(^{*}\right) P<0.05,\left(^{* *}\right)$ $P<0.01$, n.s., not significant, unpaired t-tests.

to affect cis regulatory elements (Fig. 5A). Therefore, we applied our improved protocol for the efficient targeted knock-in to insert a $131 \mathrm{bp}$ SV40 poly(A) signal into the malat1 locus in zebrafish (Fig. 5B; see Materials and Methods; Supplemental Fig. 4A). The targeted knock-in of the poly(A) sequence completely abolished malat1 expression in zebrafish embryos and in all examined adult tissues (Fig. 5C,D; Supplemental Fig. 4B,C). Despite effective inactivation of malat1, malat ${ }^{\text {poly(A) }}$ zebrafish were viable and fertile and displayed no obvious morphological defects. The lack of overall morphological abnormalities is consistent with previously reported Malat $1^{-1-}$ mice (Eissmann et al. 2012; Nakagawa et al. 2012; Zhang et al. 2012) and is in contrast to morpholino-based malat1 inactivation in zebrafish (Wu et al. 2018). Taken together, compared to IncRNA deletion strategies, poly $(A)$ signal insertion was the most efficient and least invasive approach in zebrafish.

\section{DISCUSSION}

The identification of IncRNAs in model vertebrates, their comparative genomics analyses and recent progress in genome editing technologies has led to the generation of multiple mutant IncRNA alleles. Because common strategies for genetic inactivation of IncRNAs often do not allow distinguishing between functions mediated by the IncRNA transcript and those mediated by overlapping DNA regulatory motifs, the generation and interpretation of IncRNA null alleles can be challenging. Here, we compared zebrafish IncRNA mutant alleles generated using several alternative and commonly applied CRISPR-Cas9 strategies for IncRNA inactivation.

We demonstrated that relatively small deletions of conserved regions of IncRNAs, which represent attractive target sequences to eliminate or diminish IncRNA functions (Bitetti et al. 2018; Kleaveland et al. 2018), might result in unexpected changes in IncRNA levels, such as overexpression of the remaining transcript, as demonstrated for cyrano. One possibility is that deletion of the conserved region of cyrano, which removed a highly conserved and extensively paired site to miR-7 (Ulitsky et al. 2011), stabilized the cyrano transcript in zebrafish. Alternatively, deletion of this region of cyrano in zebrafish might have caused transcriptional up-regulation. For example, if deletion of this region abrogated cyrano function, cells might have boosted transcription of the locus in an attempt to restore cyrano activity. Deletion of the conserved region of mouse cyrano does not lead to increased IncRNA levels (Kleaveland et al. 2018), which suggests that cyrano regulation has diverged between fish and mammals. A better understanding of cyrano regulation and function will help identify the source of this ectopic effect on the remaining IncRNA transcript observed in fish and how this effect might complicate interpretation of the deletion results.

Moreover, we showed that the removal of TSS and upstream regulatory regions, a commonly used approach considered to be straightforward to interpret, can result in the presence of either constitutive or tissue-specific alternative TSSs that preclude efficient inactivation of IncRNAs and result in hypomorph mutant animals. Although not shown in this study, usage of temporal-specific alternative TSSs might also contribute to the maintenance of IncRNA expression at specific developmental stages, complicating the analysis and interpretation of TSS mutant alleles in animal models. Interestingly, a recent study reported that a 326 bp deletion removing cyrano's TSS leads to loss of the IncRNA expression (Goudarzi et al. 2019). The 
A

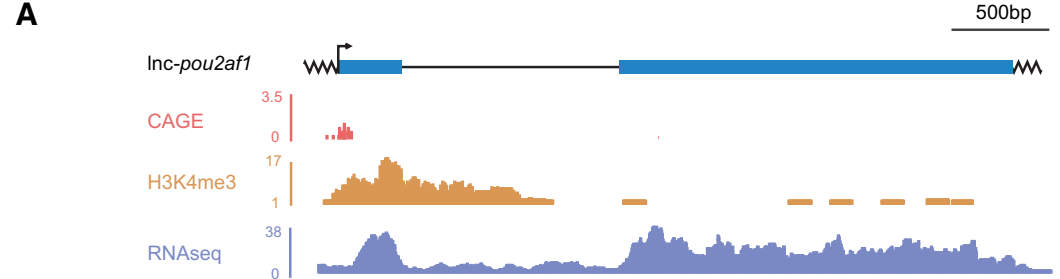

B

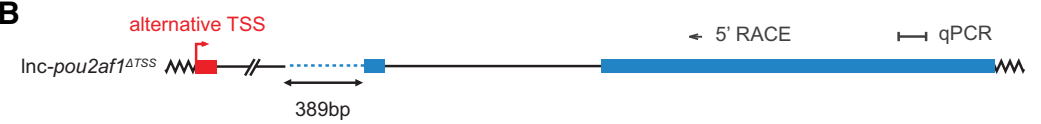

C

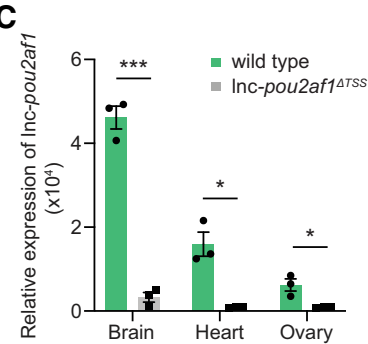

E

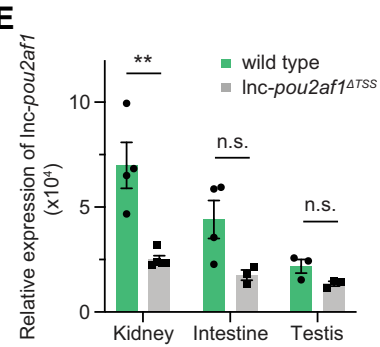

FIGURE 4. Usage of tissue-specific alternative TSSs maintains Inc-pou2af1 expression in a subset of adult tissues. (A) The Inc-pou2af1 locus in zebrafish. Shown are the corresponding CAGE (Nepal et al. 2013; Haberle et al. 2014), H3K4me3 ChIP-Seq (Ulitsky et al. 2011), and RNA-seq tracks from WT zebrafish. (B) The Inc-pou2af1 ${ }^{4 T S S}$ mutant allele showing deletion of the sequence around the TSS (dotted, blue line). Indicated are positions of the 5' RACE and qPCR primers and alternative TSS. Red box represents a new exon generated from the alternative TSS. (C-E) Inc-pou2af1 expression across a subset of adult WT and homozygous Inc-pou2af1 ${ }^{\Delta T S S}$ zebrafish tissues detected by qRT-PCR. eef1 $1 / 11$ was used as a reference gene in all qRT-PCR experiments. Each dot represents an individual biological replicate. Data are presented as mean $\pm \mathrm{S}$. E.M.; $\left(^{*}\right) P<0.05,\left(^{* *}\right) P<0.01,\left(^{* * *}\right) P<0.001$, n.s., not significant, unpaired t-tests.

difference observed between the cyrano ${ }^{\Delta T S S}$ alleles may be a consequence of the larger deletion used by Goudarzi et al. potentially leading to a more effective down-regulation of cyrano. In addition, the choice of the IncRNA detection method as well as the developmental timing of detection are important. Our data show that in TSS deletion alleles, IncRNA expression is often abolished at early embryonic stages and robustly reestablished later during development by tissue-specific alternative TSSs. These collective observations underscore the necessity to carefully validate TSS deletion alleles.

Importantly, our improved protocol for efficient targeted knock-in in zebrafish enabled examination of the effect of a poly(A) signal insertion into the most abundant and enhancer-dense IncRNA locus. We demonstrate that this minimally invasive genome editing strategy, previously shown to be successful for IncRNA inactivation in mice (Grote et al. 2013; Anderson et al. 2016; Isoda et al. 2017; Ballarino et al. 2018), is a highly effective strategy in zebrafish. Given the ease of our knock-in approach, which combines the use of a single-strand oligo as a template for homologous recombination and inhibition of nonhomologous end joining, we anticipate that the insertion of a poly $(A)$ sequence will become a widespread strategy for generating IncRNA mutant alleles in zebrafish. Furthermore, the knock-in strategy can be used for genetic tagging of IncRNAs with selfcleaving ribozymes, which has been demonstrated to perturb IncRNA expression in mouse embryonic stem cells (Tuck et al. 2018) but has not been tested yet in model organisms.

Taken together, evaluation of several independent IncRNA mutant alleles in zebrafish indicates that a combination of complementary IncRNA inactivation approaches and their careful analyses are required for robust and accurate IncRNA functional interrogation.

\section{MATERIALS AND METHODS}

\section{Generation of IncRNA mutant alleles in zebrafish}

All IncRNA mutant alleles were generated using CRISPR/Cas9-mediated genome editing. To generate Inc-sox $4 a^{\Delta T S S}$, Incpou2af1 $^{\Delta T S S}$, cyrano ${ }^{\Delta T S S}$, and cyrano ${ }^{\Delta C R}$ alleles, two sgRNAs ( 9 ng each, Supplemental Table 1) and $150 \mathrm{ng}$ in vitro transcribed Cas9 mRNA were coinjected into the one-cell stage $A B$ zebrafish embryos (Hwang et al. 2013). To generate Inc-sox4$a^{\Delta 3^{\prime} \text { exon }}$ allele, two sgRNAs (100 ng each, Supplemental Table 1) and Cas9 protein $(50 \mathrm{ng} / \mu \mathrm{L}$, a gift of the Concordet Lab, Muséum d'Histoire Naturelle, Paris) were coinjected into the one-cell stage $A B$ zebrafish embryos (Hwang et al. 2013). sgRNAs and Cas9 mRNA were generated as described previously (Hwang et al. 2013), using the codon-optimized plasmid JDS246 for the Cas9 mRNA synthesis (Addgene \#43861), purified with RNeasyMini Kit (Qiagen). Genomic DNA was extracted as described previously (Bitetti et al. 2018) and used for genotyping by PCR, DNA sequencing and mapping of genetic amplification product. The genotyping primers are listed in Supplemental Table 2.

All zebrafish were bred and maintained at Institut Curie, Paris. Animal care and use for this study were performed in accordance with the recommendations of the European Community (2010/63/UE) for the care and use of laboratory animals. Experimental procedures were specifically approved by the ethics committee of Institut Curie CEEA-IC \#118 (project CEEA-IC 2017-017) in compliance with the international guidelines. Zebrafish were staged using standard procedures (Kimmel et al. 1995).

\section{Generation of the malat $1^{\text {poly(A) }}$ allele by CRISPR/ Cas9-mediated homologous recombination in zebrafish}

The CRISPR/Cas9-mediated knock-in protocol was optimized as described in Supplemental Figure 4A. Zebrafish malat ${ }^{\text {poly(A) }}$ mutant was generated by insertion of a single SV40 poly(A) signal 
A

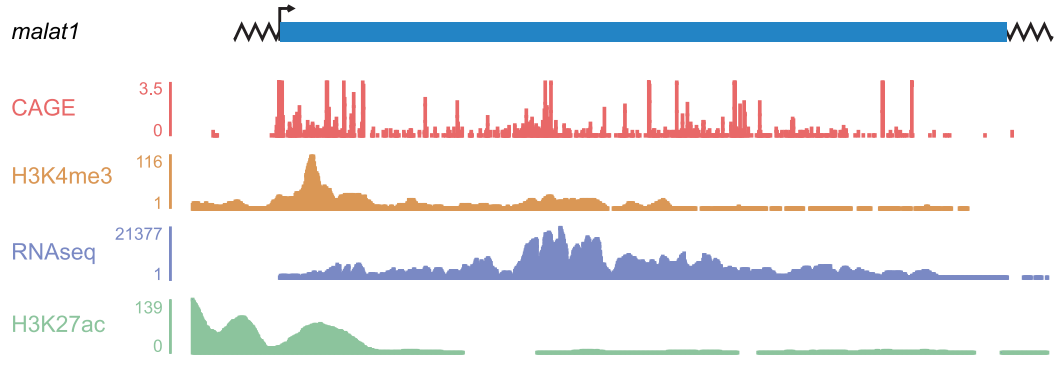

B

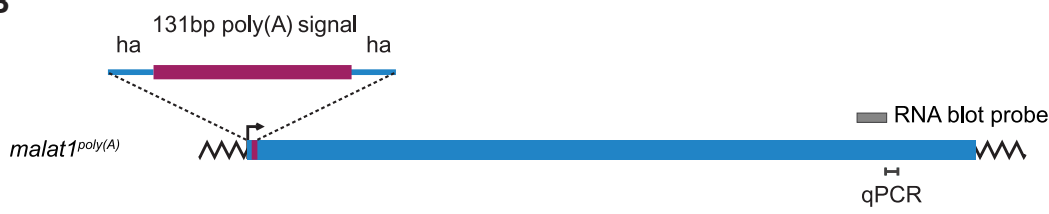

C

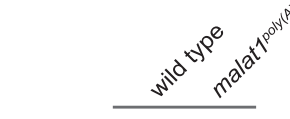

malat1
D

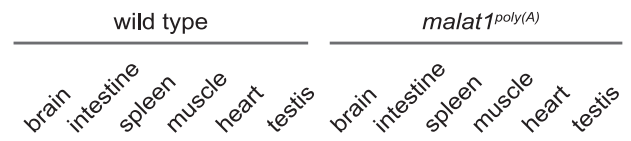

malat1

18S rRNA
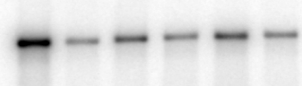

18S rRNA

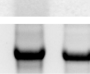

FIGURE 5. Effective inactivation of the IncRNA malat1 in zebrafish by insertion of a premature polyadenylation signal. (A) The malat1 locus in zebrafish. Shown are the corresponding CAGE (Nepal et al. 2013; Haberle et al. 2014), H3K4me3 ChIP-Seq (Ulitsky et al. 2011), RNA-seq, and H3K27ac ChIP-Seq (Pérez-Rico et al. 2017) tracks from WT zebrafish. (B) Generation of the malat $1^{\text {poly(A) }}$ allele by targeted knock-in of the poly(A) signal. The hybridization site of the RNA blot probe is indicated as a gray box. ha, homology arms. (C) malat1 expression in WT and homozygous malat1 ${ }^{\text {poly(A) }}$ embryos detected by an RNA blot. 18S rRNA was used as a loading reference. hpf, hours postfertilization. (D) malat1 expression across WT and homozygous malat $1^{\text {poly(A) }}$ adult zebrafish tissues detected by RNA blot. 18S rRNA was used as a loading reference. ment (TURBO DNA-free Ambion). For individual replicates, RNA isolated from 30-100 embryos or tissues from one to six adult fish was used. CDNA was produced with SuperScript IV reverse transcriptase (Invitrogen) and amplified with PowerUp SYBR Green PCR Master Mix (ThermoFisher Scientific) using primers listed in Supplemental Table 3. For each biological replicate, qRT-PCRs were performed in technical triplicate. The eef1 $\alpha 1 / 1$ (eukaryotic translation elongation factor 1 alpha 1, like 1) was used as a reference gene (McCurley and Callard 2008).

\section{RNA blots}

Total RNA was isolated using TRIzol (Invitrogen), separated on $1 \%$ agarose gels containing $0.8 \%$ formaldehyde, and transferred to nylon membrane (Nytran SPC, GE Healthcare) by capillary action. Blots were hybridized with $\alpha$-UTP ${ }^{32} \mathrm{P}$-labeled RNA probes at $68^{\circ} \mathrm{C}$ in ULTRAhyb buffer (Ambion) as recommended by the manufacturer. RNA probe template was amplified from zebrafish brain cDNA by PCR using the primers listed in Supplemental Table 3 (the sequence of the T7 promoter is underlined) and in vitro transcribed (RNA Maxiscript, Ambion) in the presence of $\alpha$-UTP ${ }^{32} P$. For each replicate, RNA isolated from 30-100 embryos or tissues from three to six adult fish was used. The gel blots and hybridizations in Figure 5C were performed in biological triplicates. The hybridizations in Figures $2 \mathrm{~F}$ and $5 \mathrm{D}$ were performed once.
(131 bp) into the malat1 locus. Briefly, one-cell stage embryos were injected with a single guide RNA (100 ng, Supplemental Table 1), Cas9 protein ( $50 \mathrm{ng} / \mu \mathrm{L}$, a gift of the Concordet laboratory, Muséum d'Histoire Naturelle, Paris), a morpholino against xrcc4 to suppress NHEJ (nonhomologous end joining) (3 ng/ $\mu \mathrm{L}$, Gene Tools LLC, Supplemental Table 1), and a 191 nt singlestrand DNA oligo with 30 bp homology arms flanking both sides of the SV40 poly(A) sequence (200 ng, designed and manufactured by Ultramer IDT, Supplemental Table 1). Genomic DNA was extracted as described previously (Bitetti et al. 2018), and poly $(A)$ insertion was detected by PCR using primers listed in Supplemental Table 2, DNA sequencing and mapping of genetic amplification product.

\section{qRT-PCR}

Total RNA was isolated from zebrafish embryos and adult tissues by TRIzol extraction (Invitrogen) followed by DNase treat-

\section{RNA ligase-mediated and oligo-capping rapid amplification of $c D N A$ ends (5' RACE)}

TSS usage was determined by rapid amplification of cDNA ends (RACE) according to manufacturer's instruction (GeneRacer kit, Life Technology). Gene specific primers listed in Supplemental Table 3 were used to amplify IncRNA 5' RACE products through PCR and nested PCR, subcloned into the PCR BLUNT II TOPO vector (Invitrogen), and transformed in the NEB TOP10 cells. A minimum of 12 colonies were sequenced, and the sequences were aligned to the corresponding IncRNA genomic locus.

\section{SUPPLEMENTAL MATERIAL}

Supplemental material is available for this article. 


\section{ACKNOWLEDGMENTS}

We thank all members of the Shkumatava laboratory and Ines Drinnenberg for useful discussions. This work was supported by grants from the European Research Council (FLAME-337440), ATIP-Avenir, La Fondation Bettencourt Schueller, ANR-11LABX-0044_DEEP, and ANR-10-IDEX-0001-02, as well as PSL and La Ligue Nationale Contre Le Cancer doctoral fellowships to P.L.

Author contributions: P.L. developed the protocol for the targeted knock-in in zebrafish and contributed to the design, generation, and analysis of the $\operatorname{lnc}$-sox $4 a^{\Delta T S S}, \operatorname{lnc}$-sox $4 a^{\Delta 3^{\prime} \text { exon }}$, and malat ${ }^{\text {poly(A) }}$ alleles. H.E. contributed to the design, generation, and analysis of the Inc-pou2af1 ${ }^{\Delta T S S}$ and the maintenance and analyses of IncRNA alleles. L.D and F.C. contributed to IncRNA expression analyses and the maintenance of IncRNA alleles. S. M. contributed to the design, generation, and analyses of the cyrano alleles. A.B. contributed to the design, generation, and analyses of the malat $1^{\text {poly(A) }}$ allele. A.G. contributed to the design and generation of the cyrano alleles. P.L. and A.S. wrote the final version of the manuscript. A.S. conceived and supervised the study.

Received November 2, 2018; accepted April 27, 2019.

\section{REFERENCES}

Amândio AR, Necsulea A, Joye E, Mascrez B, Duboule D. 2016. Hotair is dispensible for mouse development. PLoS Genet 12: e1006232. doi:10.1371/journal.pgen.1006232

Anderson KM, Anderson DM, McAnally JR, Shelton JM, BasselDuby R, Olson EN. 2016. Transcription of the non-coding RNA upperhand controls Hand2 expression and heart development. Nature 539: 433-436. doi:10.1038/nature20128

Ballarino M, Cipriano A, Tita R, Santini T, Desideri F, Morlando M, Colantoni A, Carrieri C, Nicoletti C, Musarò A, et al. 2018. Deficiency in the nuclear long noncoding RNA Charme causes myogenic defects and heart remodeling in mice. EMBO J 37: e99697. doi:10.15252/embj.201899697

Bitetti A, Mallory AC, Golini E, Carrieri C, Carreño Gutiérrez H, Perlas E, Pérez-Rico YA, Tocchini-Valentini GP, Enright AJ, Norton WHJ, et al. 2018. MicroRNA degradation by a conserved target RNA regulates animal behavior. Nat Struct Mol Biol 25: 244-251. doi:10.1038/s41594-018-0032-x

Bond AM, Vangompel MJ, Sametsky EA, Clark MF, Savage JC, Disterhoft JF, Kohtz JD. 2009. Balanced gene regulation by an embryonic brain ncRNA is critical for adult hippocampal GABA circuitry. Nat Neurosci 12: 1020-1027. doi:10.1038/nn.2371

Eissmann $M$, Gutschner T, Hämmerle $M$, Günther $S$, CaudronHerger M, Gross M, Schirmacher P, Rippe K, Braun T, Zörnig M, et al. 2012. Loss of the abundant nuclear non-coding RNA MALAT1 is compatible with life and development. RNA Biol 9: 1076-1087. doi:10.4161/rna.21089

Fitzpatrick GV, Soloway PD, Higgins MJ. 2002. Regional loss of imprinting and growth deficiency in mice with a targeted deletion of KvDMR1. Nat Genet 32: 426-431. doi:10.1038/ng988

Goff LA, Rinn JL. 2015. Linking RNA biology to IncRNAs. Genome Res 25: 1456-1465. doi:10.1101/gr.191122.115

Goudarzi M, Berg K, Pieper LM, Schier AF. 2019. Individual long noncoding RNAs have no overt functions in zebrafish embryogenesis, viability and fertility. Elife 8: e40815. doi:10.7554/eLife.40815

Grote P, Wittler L, Hendrix D, Koch F, Währisch S, Beisaw A, Macura K, Bläss G, Kellis M, Werber M, et al. 2013. The tissue-specific IncRNA Fendrr is an essential regulator of heart and body wall de- velopment in the mouse. Dev Cell 24: 206-214. doi:10.1016/j .devcel.2012.12.012

Haberle V, Li N, Hadzhiev Y, Plessy C, Previti C, Nepal C, Gehrig J, Dong X, Akalin A, Suzuki AM, et al. 2014. Two independent transcription initiation codes overlap on vertebrate core promoters. Nature 507: 381-385. doi:10.1038/nature12974

Han P, Li W, Lin CH, Yang J, Shang C, Nuernberg ST, Jin KK, Xu W, Lin CY, Lin CJ, et al. 2014. A long noncoding RNA protects the heart from pathological hypertrophy. Nature 514: 102-106. doi:10.1038/nature13596

Han X, Luo S, Peng G, Lu JY, Cui G, Liu L, Yan P, Yin Y, Liu W, Wang $R$, et al. 2018. Mouse knockout models reveal largely dispensable but context-dependent functions of IncRNAs during development. J Mol Cell Biol 10: 175-178. doi:10.1093/jmcb/ mjy003

Hezroni H, Koppstein D, Schwartz MG, Avrutin A, Bartel DP, Ulitsky I. 2015. Principles of long noncoding RNA evolution derived from direct comparison of transcriptomes in 17 species. Cell Rep 11: 1110-1122. doi:10.1016/j.celrep.2015.04.023

Hosono Y, Niknafs YS, Prensner JR, lyer MK, Dhanasekaran SM, Mehra R, Pitchiaya S, Tien J, Escara-Wilke J, Poliakov A, et al. 2017. Oncogenic role of THOR, a conserved cancer/testis long non-coding RNA. Cell 171: 1559-1572 e1520. doi:10.1016/j.cell 2017.11.040

Hwang WY, Fu Y, Reyon D, Maeder ML, Kaini P, Sander JD, Joung JK, Peterson RT, Yeh JR. 2013. Heritable and precise zebrafish genome editing using a CRISPR-Cas system. PLoS One 8: e68708. doi:10.1371/journal.pone.0068708

Ip JY, Sone M, Nashiki C, Pan Q, Kitaichi K, Yanaka K, Abe T, Takao K, Miyakawa T, Blencowe BJ, et al. 2016. Gomafu IncRNA knockout mice exhibit mild hyperactivity with enhanced responsiveness to the psychostimulant methamphetamine. Sci Rep 6: 27204 doi:10.1038/srep27204

Isoda T, Moore AJ, He Z, Chandra V, Aida M, Denholtz M, Piet van Hamburg J, Fisch KM, Chang AN, Fahl SP, et al. 2017. Non-coding transcription instructs chromatin folding and compartmentalization to dictate enhancer-promoter communication and T cell fate. Cell 171: 103-119 e118. doi:10.1016/j.cell.2017 .09 .001

Kimmel CB, Ballard WW, Kimmel SR, Ullmann B, Schilling TF. 1995. Stages of embryonic development of the zebrafish. Dev Dyn 203: 253-310. doi:10.1002/aja.1002030302

Kleaveland B, Shi CY, Stefano J, Bartel DP. 2018. A network of noncoding regulatory RNAs acts in the mammalian brain. Cell 174: 350-362 e317. doi:10.1016/j.cell.2018.05.022

Kok FO, Shin M, Ni CW, Gupta A, Grosse AS, van Impel A, Kirchmaier BC, Peterson-Maduro J, Kourkoulis G, Male I, et al. 2015. Reverse genetic screening reveals poor correlation between morpholino-induced and mutant phenotypes in zebrafish. Dev Cell 32: 97-108. doi:10.1016/j.devcel.2014.11.018

Kotzin JJ, Spencer SP, McCright SJ, Kumar DBU, Collet MA, Mowel WK, Elliott EN, Uyar A, Makiya MA, Dunagin MC, et al. 2016. The long non-coding RNA Morrbid regulates Bim and short-lived myeloid cell lifespan. Nature 537: 239-243. doi:10 .1038/nature19346

Lai KM, Gong G, Atanasio A, Rojas J, Quispe J, Posca J, White D, Huang M, Fedorova D, Grant C, et al. 2015. Diverse phenotypes and specific transcription patterns in twenty mouse lines with ablated lincRNAs. PLoS One 10: e0125522. doi:10.1371/journal .pone.0125522

Leighton PA, Ingram RS, Eggenschwiler J, Efstratiadis A, Tilghman SM. 1995. Disruption of imprinting caused by deletion of the H19 gene region in mice. Nature 375: 34-39. doi:10 $.1038 / 375034 a 0$ 
Li L, Liu B, Wapinski OL, Tsai MC, Qu K, Zhang J, Carlson JC, Lin M Fang F, Gupta RA, et al. 2013. Targeted disruption of Hotair leads to homeotic transformation and gene derepression. Cell Rep 5: 312. doi:10.1016/j.celrep.2013.09.003

Marahrens Y, Panning B, Dausman J, Strauss W, Jaenisch R. 1997. Xist-deficient mice are defective in dosage compensation but not spermatogenesis. Genes Dev 11: 156-166. doi:10.1101/gad .11.2.156

McCurley AT, Callard GV. 2008. Characterization of housekeeping genes in zebrafish: male-female differences and effects of tissue type, developmental stage and chemical treatment. BMC Mol Biol 9: 102. doi:10.1186/1471-2199-9-102

Nakagawa S, Ip JY, Shioi G, Tripathi V, Zong X, Hirose T, Prasanth KV. 2012. Malat1 is not an essential component of nuclear speckles in mice. RNA 18: 1487-1499. doi:10.1261/rna.033217.112

Nakagawa S, Shimada M, Yanaka K, Mito M, Arai T, Takahashi E, Fujita Y, Fujimori T, Standaert L, Marine JC, et al. 2014. The IncRNA Neat 1 is required for corpus luteum formation and the establishment of pregnancy in a subpopulation of mice. Development 141: 4618-4627. doi:10.1242/dev.110544

Necsulea A, Soumillon M, Warnefors M, Liechti A, Daish T, Zeller U, Baker JC, Grützner F, Kaessmann H. 2014. The evolution of IncRNA repertoires and expression patterns in tetrapods. Nature 505: 635-640. doi:10.1038/nature12943

Nepal C, Hadzhiev Y, Previti C, Haberle V, Li N, Takahashi H, Suzuki AM, Sheng Y, Abdelhamid RF, Anand S, et al. 2013. Dynamic regulation of the transcription initiation landscape at single nucleotide resolution during vertebrate embryogenesis. Genome Res 23: 1938-1950. doi:10.1101/gr.153692.112

Pérez-Rico YA, Boeva V, Mallory AC, Bitetti A, Majello S, Barillot E, Shkumatava A. 2017. Comparative analyses of super-enhancers reveal conserved elements in vertebrate genomes. Genome Res 27: 259-268. doi:10.1101/gr.203679.115

Ripoche MA, Kress C, Poirier F, Dandolo L. 1997. Deletion of the H19 transcription unit reveals the existence of a putative imprinting control element. Genes Dev 11: 1596-1604. doi:10.1101/gad .11.12.1596

Sado T, Wang Z, Sasaki H, Li E. 2001. Regulation of imprinted X-chromosome inactivation in mice by Tsix. Development 128: 12751286.

Sarangdhar MA, Chaubey D, Srikakulam N, Pillai B. 2018. Parentally inherited long non-coding RNA Cyrano is involved in zebrafish neurodevelopment. Nucleic Acids Res 46: 9726-9735. doi:10 $.1093 /$ nar/gky628

Sauvageau M, Goff LA, Lodato S, Bonev B, Groff AF, Gerhardinger C, Sanchez-Gomez DB, Hacisuleyman E, Li E, Spence M, et al. 2013. Multiple knockout mouse models reveal lincRNAs are required for life and brain development. Elife 2: e01749. doi:10.7554/eLife .01749

Sleutels F, Zwart R, Barlow DP. 2002. The non-coding air RNA is required for silencing autosomal imprinted genes. Nature 415: 810-813. doi:10.1038/415810a

Tuck AC, Natarajan KN, Rice GM, Borawski J, Mohn F, Rankova A, Flemr M, Wenger A, Nutiu R, Teichmann S, et al. 2018. Distinctive features of lincRNA gene expression suggest widespread RNA-independent functions. Life Sci Alliance 1: e201800124. doi:10 .26508/Isa.201800124

Ulitsky I, Shkumatava A, Jan CH, Sive H, Bartel DP. 2011. Conserved function of lincRNAs in vertebrate embryonic development despite rapid sequence evolution. Cell 147: 1537-1550. doi:10 .1016/j.cell.2011.11.055

Wu M, Zhang S, Chen X, Xu H, Li X. 2018. Expression and function of IncRNA MALAT-1 in the embryonic development of zebrafish. Gene 680: 65-71. doi:10.1016/j.gene.2018.09.037

Zhang B, Arun G, Mao YS, Lazar Z, Hung G, Bhattacharjee G, Xiao X, Booth CJ, Wu J, Zhang C, et al. 2012. The IncRNA Malat1 is dispensable for mouse development but its transcription plays a cis-regulatory role in the adult. Cell Rep 2: 111-123. doi:10 .1016/j.celrep.2012.06.003 
RNA 25: 897-904 (2019)

\title{
Corrigendum: Strategies for genetic inactivation of long noncoding RNAs in zebrafish
}

\author{
PERRINE LAVALOU, HELENE ECKERT, LOUISE DAMY, FLORIAN CONSTANTY, SARA MAJELLO, \\ ANGELO BITETTI, ANTOINE GRAINDORGE, and ALENA SHKUMATAVA
}

In the Acknowledgment section of the above-mentioned article, the authors omitted the funding sources ANR-11-LABX0044_DEEP and ANR-10-IDEX-0001-02. The Acknowledgment section has been corrected online to read as follows:

We thank all members of the Shkumatava laboratory and Ines Drinnenberg for useful discussions. This work was supported by grants from the European Research Council (FLAME-337440), ATIP-Avenir, La Fondation Bettencourt Schueller, ANR11-LABX-0044_DEEP, and ANR-10-IDEX-0001-02, as well as PSL and La Ligue Nationale Contre Le Cancer doctoral fellowships to P.L.

doi: $10.1261 /$ rna.074989.120 

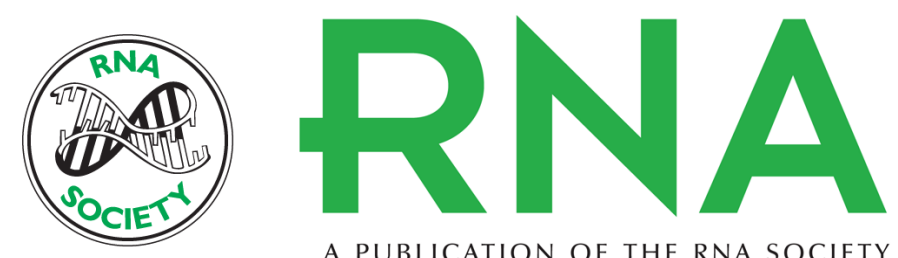

A PUBLICATION OF THE RNA SOCIETY

\section{Strategies for genetic inactivation of long noncoding RNAs in zebrafish}

Perrine Lavalou, Helene Eckert, Louise Damy, et al.

RNA 2019 25: 897-904 originally published online May 1, 2019

Access the most recent version at doi:10.1261/rna.069484.118

\section{Supplemental http://rnajournal.cshlp.org/content/suppl/2019/05/01/rna.069484.118.DC1 \\ Material}

Related Content

References

Open Access

Creative Commons

License

Email Alerting Service
Corrigendum: Strategies for genetic inactivation of long noncoding RNAs in zebrafish

Perrine Lavalou, Helene Eckert, Louise Damy, et al.

RNA April , 2020 26: 529

This article cites 41 articles, 10 of which can be accessed free at: http://rnajournal.cshlp.org/content/25/8/897.full.html\#ref-list-1

Articles cited in: http://rnajournal.cshlp.org/content/25/8/897.full.html\#related-urls

Freely available online through the RNA Open Access option.

This article, published in RNA, is available under a Creative Commons License (Attribution 4.0 International), as described at

http://creativecommons.org/licenses/by/4.0/.

Receive free email alerts when new articles cite this article - sign up in the box at the top right corner of the article or click here.

\section{|||||||| Providing Precise Solutions for} your research.

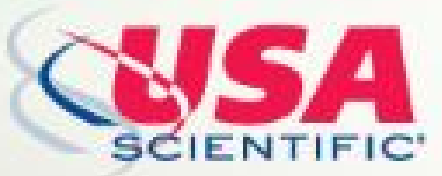

To subscribe to RNA go to:

http://rnajournal.cshlp.org/subscriptions

(C) 2019 Lavalou et al.; Published by Cold Spring Harbor Laboratory Press for the RNA Society 